$1-1-2007$

\title{
Tumour Suppressor Function of RNase L in A Mouse Model
}

Wendy Liu

Case Western Reserve University

Shu Ling Liang

Johns Hopkins University

Hongli Liu

Cleveland State University

Robert Silverman

Cleveland State University, R.SILVERMAN33@csuohio.edu

Aimin Zhou

Cleveland State University, A.ZHOU@csuohio.edu

Follow this and additional works at: https://engagedscholarship.csuohio.edu/scichem_facpub

Part of the Chemistry Commons

How does access to this work benefit you? Let us know!

\section{Recommended Citation}

Liu, Wendy; Liang, Shu Ling; Liu, Hongli; Silverman, Robert; and Zhou, Aimin, "Tumour Suppressor Function of RNase L in A Mouse Model" (2007). Chemistry Faculty Publications. 422.

https://engagedscholarship.csuohio.edu/scichem_facpub/422

This Article is brought to you for free and open access by the Chemistry Department at EngagedScholarship@CSU. It has been accepted for inclusion in Chemistry Faculty Publications by an authorized administrator of EngagedScholarship@CSU. For more information, please contact library.es@csuohio.edu. 


\title{
Tumour suppressor function of $R$ Nase $L$ in a mouse model
}

\author{
Wendy Liu , Shu-Ling Liang, Hongli Liu , Robert Silverman , Aimin Zhou
}

\section{Introduction}

Interferons (IFNs) are a family of cytokines participating in in nate immunity against a wide range of viruses and other microbial pathogens.1 IFNs also have anti tumour activities due to their anti proliferative, immunoregulatory and apopto tic properties.2 The effects of IFNs are largely mediated through proteins encoded by IFN stimulated genes (ISGs). One well studied ISG is RNase L, which is one of the key en zymes in the IFN induced 2 SA system. ${ }^{3}$ The 2 SA system con sists of two types of enzymes: 2 SA synthetases and RNase L4
IFNs induce a family of 2 SA synthetase genes. The 2 SA syn thetases require double stranded RNA (dsRNA) for their activ ities. After activation by dsRNA which is frequently produced during viral infection, 2 SA synthetases convert ATP molecules to pyrophosphate (ppi) and a series of unique, 5 phosphory lated, 2 ' 5 linked oligoadenylates known as 2 SA with the gen era! formula ppp(A2'p5')nA ( $\cdots$; 2). 2 SA binds RNase L with high affinity, converting it from its inactive, monomeric state to a potent dimeric endoribonuclease, resulting in degradation of single stranded viral and cellular RNAs. The 2 SA system mediates host defence against certain types of viruses. The 
overexpression of RNase L in NIH 3T3 cells markedly enhances the antiviral function of IFN, whereas the dominant negative RNase L suppresses the antiviral activity of IFN in SVT2 cells., 6 Mice containing homozygous disruption of the RNase L gene succumbs to encephalomyocarditis (EMCV) infection more rapidly than infected wild type mice. ${ }^{7}$ A broad range of viruses including HIV 1, vaccinia virus, human parainfluenza virus 3, vesicular stomatitis virus, and EMCV have shown to be inhib ited in RNase L overexpressing cell lines. ${ }^{8}$

RNase $\mathrm{L}$ has been linked to apoptosis in response to viral and non viral agents. RNase L null mice show enlarged thy mus glands at early ages, suggesting that RNase L may be in volved in $\mathrm{T}$ cell development. In situ assays for DNA fragmentation on tissue sections from both the thymus and spleen reveal a reduction in apoptosis in the untreated RNase L ' mice compared to the cognate wild type mice. ${ }^{7}$ The direct activation of RNase $\mathrm{L}$ by introducing $25 \mathrm{~A}$ into intact cells leads to apoptosis, whereas a dominant negative RNase L de creases the numbers of apoptotic cells generated by poliovi rus infection, IFN and poly (I):poly (C) as well as staurosporine treatments. ${ }^{9-11} \mathrm{~A}$ recent study revealed that RNase $\mathrm{L}$ mediates virus induced apoptosis through activating C Jun $\mathrm{NH}_{2}$ terminal kinase (JNK). ${ }^{12}$

The evidence has shown that RNase L plays a role in cancer biology. The ARG462GLN variant of RNase L, which has an attenuated enzymatic activity, is implicated in up to $13 \%$ of prostate cancer cases. Individuals heterozygous for these mutations exhibit a $150 \%$ increased risk of prostate cancer, and homozygotes have greater than double of the risk, under scoring the importance of inactivating RNase L in the etiology of prostate cancer. ${ }^{13-16}$ The inhibitory effect of RNase L on tu mour formation is believed to be due in part to its anti prolif erative and pro apoptotic roles. However, no spontaneous tumour formation has been observed in one year old RNase L ' mice. The effect of RNase L on tumourigenesis induced by carcinogens is under investigation in our laboratory. Previ ously we have reported that the overexpression of RNase L in murine NIH 3T3 cells increased IFN anti proliferative func tion. ${ }^{5}$ In this study, we have found that bone marrow cells defi cient in RNase L grew significantly faster compared to wild type cells in response to granulate macrophage colony stimu lating factor (GM CSF), suggesting that RNase L regulates cell proliferation stimulated by other growth factors. To determine the direct impact of RNase L on tumour growth in the absence of IFN induced proteins, we have stably expressed RNase L in P 57 cells, an aggressive mouse fibrosarcoma cell line. To as sess the effect of RNase L expression on the ability of $p 57$ cells to form tumours, these cells were implanted in athymic mice. Results showed that tumour formation was significantly de layed and the tumours grew much slower in the group with RNase L (P RL) compared to the control group (P Vec). Our find ings suggest that RNase L plays a critical role in the inhibition of fibrosarcoma growth in nude mice.

\section{Materials and methods}

\section{Cell culture}

RNase $\mathrm{L}^{+/+}$and / mouse embryonic fibroblasts (MEF), P 57 cells (a gift from Dr. Chaoqun Wu, Fudan University), were grown in DMEM (The Media Lab of the Central Cell Service, Cleveland Clinic Foundation) supplemented with 10\% foetal bovine serum (Biosource) and antibiotics in a humidified atmosphere of $5 \% \mathrm{CO}_{2}$ at $37^{\circ} \mathrm{C}$. Mouse bone marrow cells iso lated from RNase $\mathrm{L}^{+/+}$and / mice were grown in RPMI 1640 supplemented with $10 \%$ foetal bovine serum and $10 \mathrm{ng} / \mathrm{ml}$ murine GM CSF.

\section{Overexpression of human RNase L in P-57 Cells}

Murine fibrosarcoma cells (P 57) were transfected using Lipo factamine reagent (Invitrogen), with a mammalian expres sion vector, pcDNAneo (Invitrogen), inserted with or without human RNase L cDNA. The cells were selected in the medium containing G418 at $300 \mu \mathrm{g} / \mathrm{ml}$. Twenty drug resistant clones transfected with the human RNase L cDNA were isolated and analysed for RNase L expression by Western blot analysis. The clonal cell lines containing the vector with RNase L insert or an empty vector are referred to as P RL and P Vec, respectively.

\section{Western blot analysis}

Cells were harvested by washing twice with ice cold phos phate buffered saline (PBS) and collected with a scraper. Cyto plasmic extracts were prepared by the suspension of cell pellets in NP 40 lysis buffer $(10 \mathrm{mM}$ Tris $\mathrm{HCl}, \mathrm{pH} 8.0,5 \mathrm{mM}$ $\mathrm{Mg}(\mathrm{OAc})_{2}, 90 \mathrm{mM} \mathrm{KCl}, 0.2 \mathrm{mM} \mathrm{PMSF}, 100 \mathrm{U} / \mathrm{ml}$ aprotinin, $10 \mu \mathrm{g} / \mathrm{ml}$ leupeptin and $2 \% \mathrm{NP} 40$ ). After centrifugation at $10,000 \mathrm{~g}$ in a microcentrifuge at $4{ }^{\circ} \mathrm{C}$ for $10 \mathrm{~min}$, cell extracts (100 $\mu$ g per sample) were fractionated on SDS $10 \%$ polyacryl amide gels and transferred to PVDF membranes (Millipore). The membranes were blocked with $5 \%$ non fat milk in PBS containing $0.02 \%$ sodium azide and $0.2 \%$ (v/v) Tween 20 , and incubated with a monoclonal antibody against human RNase $\mathrm{L}$ for $1 \mathrm{~h}$ at room temperature. The membranes were then washed with PBS containing $0.2 \%$ (v/v) Tween 20 and incu bated with goat antimouse antibody conjugated with horse radish peroxidase (Cell Signaling) for $1 \mathrm{~h}$ at room temperature. After washing, RNase L was detected by a chemiluminescence method according to the manufacturer's specification (Amersham).

\section{Assay for cell proliferation}

RNase $\mathrm{L}^{+/+}$and / MEFs, P Vec and P RL cells $\left(3 \times 10^{4}\right)$ were seeded in 6 well plates, and after $1 \mathrm{~d}$, they were treated with or without $1000 \mathrm{U} / \mathrm{ml}$ of murine IFN $\alpha$ (Biosource). Fresh IFN was added again every other day. Viable cells were counted by trypan blue dye exclusion assays daily. The proliferation of RNase $\mathrm{L}^{+/+}$and / bone marrow cells was determined using the colorimetric CellTiter 96 aqueous Cell Proliferation Assay according to the instruction provided by the manufac turer (Promega). Briefly, cells $\left(1 \times 10^{4}\right.$ cells per well) were grown in 96 wells plates in the presence of $10 \mathrm{ng}$ murine GM CSF. At various times of cell growth, $50 \mu$ CellTiter 96 Aqueous reagent $(40 \% \mathrm{v} / \mathrm{v}$ dilution in $1 \times \mathrm{PBS})$ was added to each well. Plates were incubated at $37^{\circ} \mathrm{C}$ for $2 \mathrm{~h}$, and absor bance was measured at $490 \mathrm{~nm}$ with a 96 well plate reader (Spectra Max 340; Molecular Devices). 
Anchorage-independent growth assays

P RL and P Vec cells $\left(1 \times 10^{4} / \mathrm{ml}\right)$ in $2 \times$ DMEM culture med ium were mixed with an equal volume of $0.7 \%$ agar and plated onto 6 well plates with a layer of $0.6 \%$ bottom agar. The plates were incubated at $37{ }^{\circ} \mathrm{C}$ and $5 \% \mathrm{CO}_{2}$ in a humidified incubator for 10 days. The colonies were visualised under Olympus $\mathrm{CK} \times 31$ at $100 \times$ magnification.

Tumour growth in vivo

P RL and P Vec cells $\left(1 \times 10^{6}\right)$ were injected subcutaneously into the flanks of groups of five NCRNU M nude mice (Taconic Labs). Tumour volumes were measured weekly using a caliper $(H \times W \times D)$ until the animals were euthanised.

\section{Preparation of tumour tissue for microscopic examination}

Tumours were excised and fixed in 10\% Formalin (Fisher). The fixed tumours were then subjected to routine tissue process ing. The paraffin embedded tumour tissues were thin sec tioned at $5 \mu \mathrm{m}$ and mounted on glass slides. Tissues were stained with hematoxylin and eosin.

\section{Results}

\section{RNase L inhibition of cell proliferation}

To determine the role of RNase $\mathrm{L}$ in the regulation of cell pro liferation, growth rates of RNase $\mathrm{L}^{+/+}$and / MEF cells were compared in the presence or absence of $1000 \mathrm{U}$ of IFN $\alpha$ by
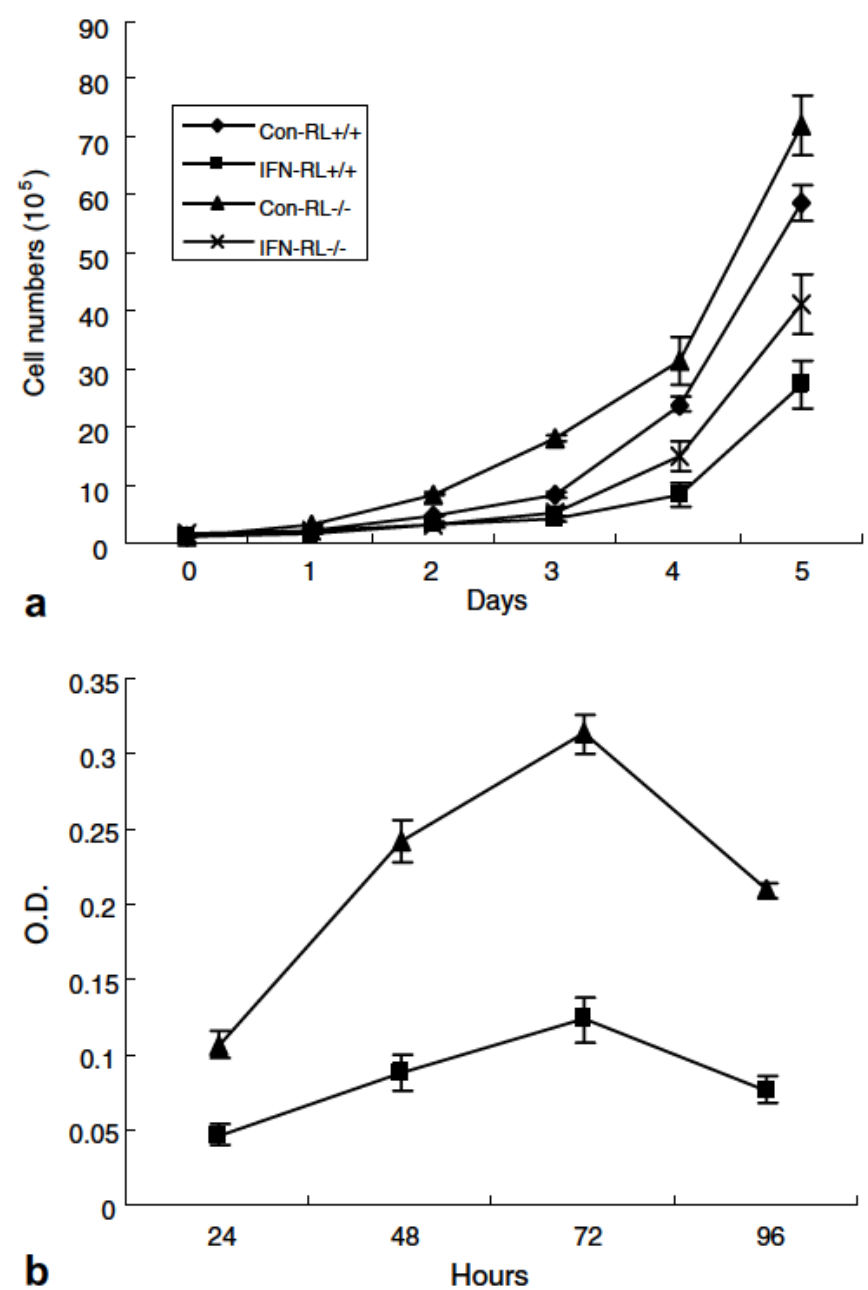

Fig. 1 - (a) Effect of RNase L on MEF proliferation. RNase $\mathrm{L}^{+/+}$and $/$MEF cells $\left(1 \times 10^{4}\right)$ were grown in DMEM supplemented with $10 \%$ FBS in six-well plates, and after $1 \mathrm{~d}$, they were treated with or without $1000 \mathrm{U} / \mathrm{ml}$ of murine IFN- $\alpha$ (Biosource). The cells were trypsinised and counted daily. Experiments were performed in triplicate, and averages of the cell counts are presented, \pm SD. Con-RL ${ }^{+/+}$: untreated wild type MEF; IFN-RL ${ }^{+/+}$: IFN-treated wild type MEF; Con-RL ${ }^{\prime}$ : untreated RNase L null MEF; IFN-RL ' : IFN-treated RNase L null MEF. (b) Effect of RNase L on murine bone marrow proliferation stimulated by GMCSF. Bone marrow cells isolated from RNase $\mathrm{L}^{+/+}$and $/$mice were cultured in RPMI 1640 supplemented with $10 \%$ FBS and $10 \mathrm{ng} / \mathrm{ml}$ murine GM-CSF (Calbiochem). Cell proliferation was determined using CellTiter 96 Non-Radioactive Cell Proliferation Assay (Promega). A treatment group consisting of six wells and independent experiments were performed twice. Data represent means \pm SD. ( $\square$ ) RNase $\mathrm{L}^{+/+}$; (A) RNase $\mathrm{L}^{\prime}$. 
measuring cell population numbers as a function of time. Both RNase $\mathrm{L}^{+/+}$and RNase L ' MEF cells were susceptible to the anti proliferative activity of IFN. There was a 2.5 fold reduction of growth rate in RNase $\mathrm{L}^{+/+}$MEF cells and a 2.0 fold reduction in RNase L ' MEF cells in the presence of IFN (Fig. 1a). These results are consistent with our previous report that there are novel pathways of IFN action against viral infection and cell proliferation. ${ }^{17}$ Surprisingly, without IFN treatment, RNase L' MEF cells grew 1.6 fold faster when compared to RNase $\mathrm{L}^{+/+}$cells. To demonstrate that the RNase $\mathrm{L}$ regulation of cell proliferation independent of IFN was not limited to specific cell type, the growth rates of bone marrow cells isolated from RNase $\mathrm{L}^{+/+}$and ' mice were compared in the presence of GM CSF. As shown in Fig. 1b, RNase L / bone marrow cells grew 1.73 fold faster when compared to RNase $\mathrm{L}^{+/+}$bone marrow cells. This result supports a broader role for RNase $\mathrm{L}$ in the control of cellular proliferation. line P-57

Expression of RNase L in the murine fibrosarcoma cell

To directly measure the effect of RNase L on tumour cell growth in the absence of other IFN induced proteins, we con stitutively expressed huRNase L cDNA in the aggressive mouse fibroblastoma cell line P 57. The huRNase L cDNA was subcloned into the HindIII site of mammalian expression vector, pcDNAneo (Invitrogen). Transfection of the P 57 cells was followed by selection in media containing G418. Three of twenty G418 resistant clones (P RL) were isolated that over expressed RNase L by about 1520 fold compared with the endogenous levels of murine RNase L in P 57 cells (Fig. 2a). The in vitro cell growth rates of the P RL cells were 1.4 folds slower when compared to the clonal cell lines containing the empty vector ( $\mathrm{P}$ Vec) in the absence of IFN. However, the overexpression of RNase L seemed not to significantly con tribute the anti proliferative effect of IFN. IFN treatment re duced the growth rate at a similar ratio in both P RL and P Vec cells (2.6:2.2) (Fig. 2b). This result was apparently different from the previous observation in NIH 3 T3 cells. ${ }^{5}$ At low cell density, the morphologic difference between P RL and P Vec cells was not obvious. However, P Vec cells continued to grow aggressively after the cells reached confluency. They piled onto each other and formed three dimensional tumour like masses with cells in elongated, spindle or fusiform shapes. On the contrary, P RL cells displayed contact inhibition when they reached full confluence. The P RL cells were large, round and polygonal (Fig. 3a). We performed a soft agar colony for mation assay to determine the anchorage independent growth of the two types of cells. As shown in Fig. 3b, colonies were clearly visualised in soft agar seeded with P Vec cells after incubation for $10 \mathrm{~d}$. In contrast, no colonies were formed in soft agar containing P RL cells.

RNase L inhibits tumour growth in vivo

To determine the impact of RNase $\mathrm{L}$ on tumour growth in vivo, P RL and P Vec cells were injected subcutaneously into the flanks of groups of five nude mice (Taconic). Tumour growth was monitored weekly with a caliper. P RL and P Vec cells a
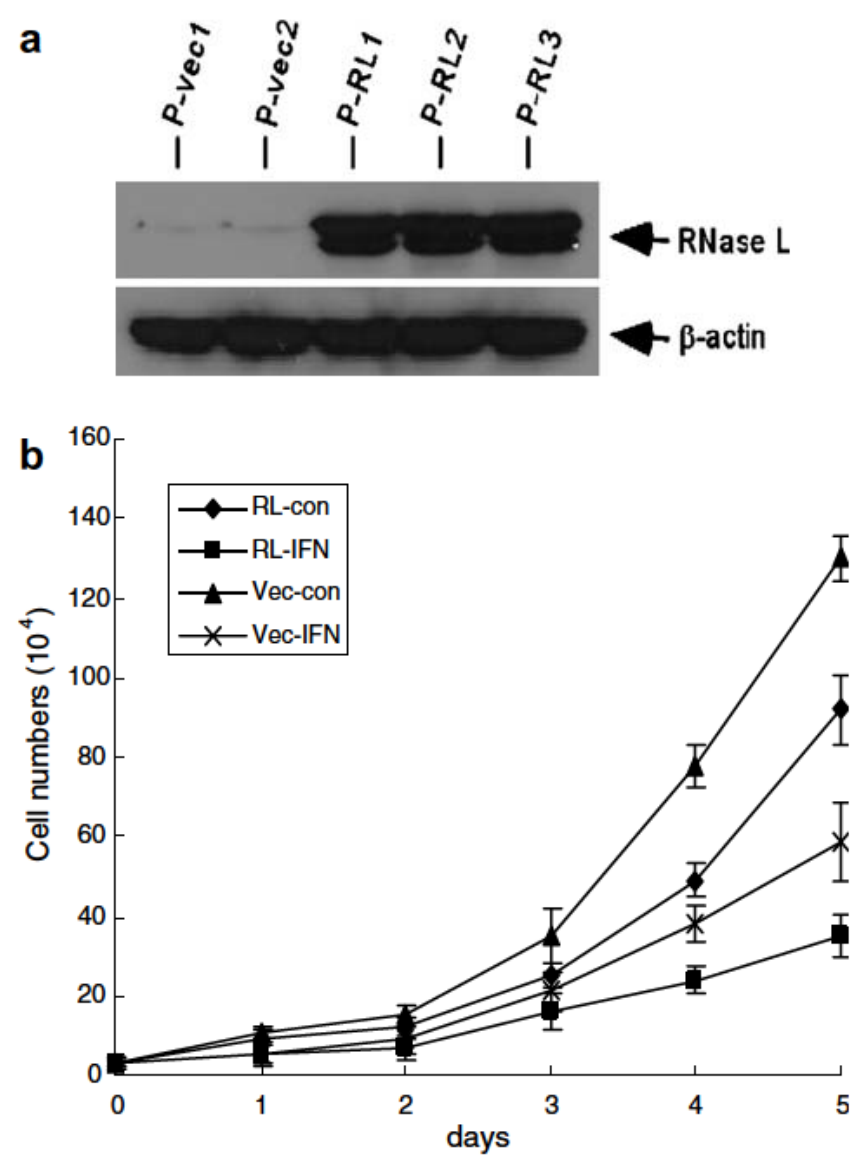

Fig. 2 - (a) Expression of human RNase L in murine P-57 fibrosarcoma cells. The huRNase L CDNA was subcloned into the HindIII site of mammalian expression vector, pcDNAneo (Invitrogen). Transfection of the P-57 cells was followed by selection in media containing G418. Expression of RNase L and $\beta$-actin in vector control clones ( $\mathrm{p}$-Vec1 and $\mathrm{p}$-Vec2) and RNase $\mathrm{L}$ gene transfected clones ( $\mathrm{p}-\mathrm{RL} 1, \mathrm{p}-\mathrm{RL} 2$ and $\mathrm{p}-\mathrm{RL}$ ) were analysed by Western blots using monoclonal antibodies to human RNase L and $\beta$-actin (Santa Cruz). (b) Effect of RNase L on P-57 cell proliferation. P-Vec and P-RL cells were grown in DMEM supplemented with $10 \%$ FBS in 6-well plates, and after $1 \mathrm{~d}$, they were treated with or without $1000 \mathrm{U} / \mathrm{ml}$ of murine IFN- $\alpha$ (Biosource). The cells were trypsinised and counted daily. Experiments were performed in triplicate, and averages of the cell counts are presented; \pm SD.

showed a dramatic difference in tumour growth (Fig. 4a). The formation of the P RL tumours was 2 weeks delayed, and P RL tumours grew markedly slower when compared with P Vec tumours. However, after 5 weeks, the growth of P RL tumours started to accelerate. Gross examination of tu mours from the P Vec cells showed that they were firm, fle shy, rounded or lobulated grey white masses, with an average volume of $1295 \mathrm{~mm}^{3}$ after five weeks. Although the tumours formed from the P RL cells have similar gross appearance, they were much smaller. The average volume of the P RL tumours was $99.2 \mathrm{~mm}^{3}$ in dimension (Fig. 4b). To 

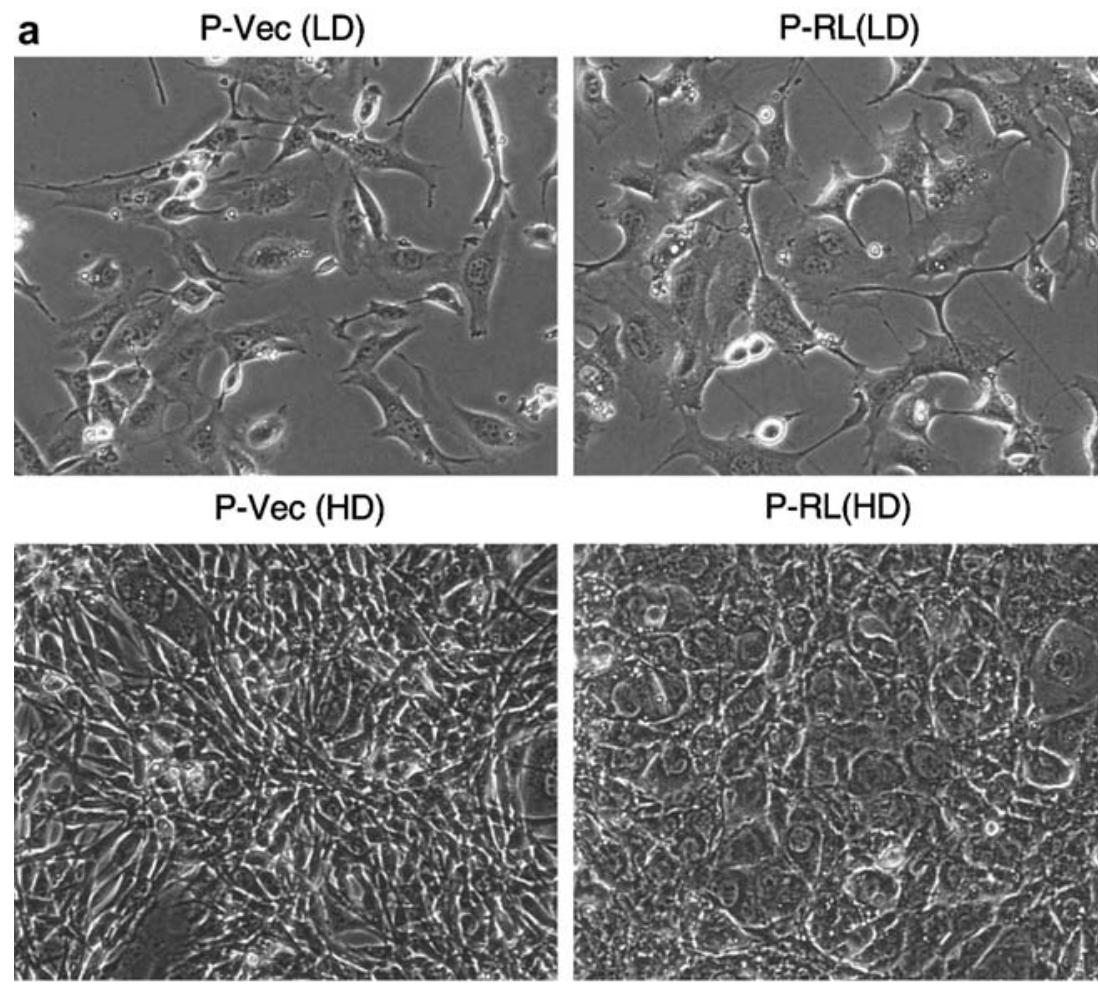

b

P-VEC
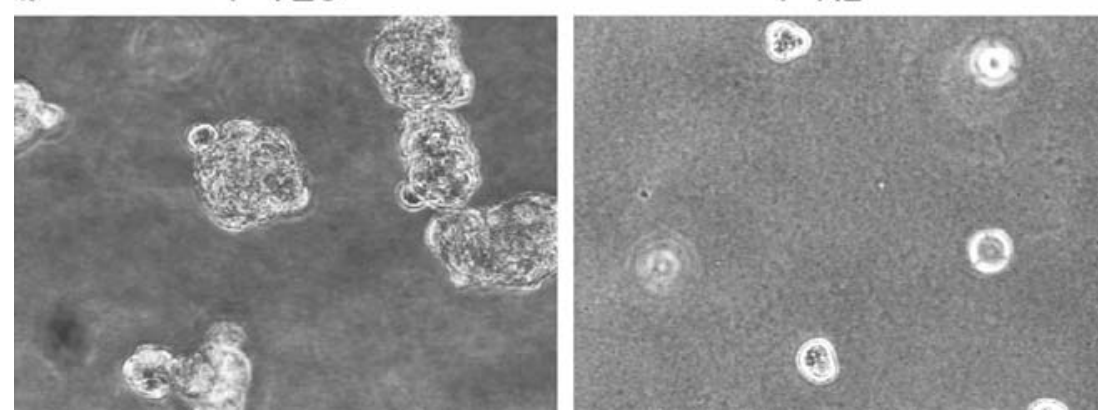

Fig. 3 - Morphology of P-RL and P-Vec cells. Photographs of the unstained cells at different growth stage (a) and colonies formed in soft agar were taken (b) under Olympus CK $\times 31$ at 100 $\times$ magnification. LD: low density; HD: high density.

rule out clonal variation as the cause of the anti tumour ef fect, we separately implanted groups of four mice with two other clones of P RL cells. The tumour results obtained from the different clones of P RL cells (data not shown) were simi lar to that from the first clone used for the experiment, thus eliminating clonal differences as the basis for the anti tu mour activity of RNase L.

Microscopically, the P Vec tumours demonstrated a uni form herringbone growth pattern consisting of spindle shaped cells that varied little in size and shape and had scant cytoplasm with indistinct cell borders (Fig. 5a). Inter estingly, dramatic differences in morphology were observed in P RL tumours (Fig. 5b), which had a less distinct fascicular or herringbone pattern. The tumour cells were epithelioid with large round and polygonal cells, open chromatin, and prominent central nucleoi. They also showed prominent pleomorphism with variable cell shape and nuclear size. This morphologic difference resembled that of the cultured cells (Fig. 3a).

\section{expression}

P-RL tumour growth is due to suppression of RNase $L$

It was possible that P RL tumours started to grow eventually in the nude mice were due to the suppression of RNase L expression by an unknown mechanism. To determine RNase L level in the tumour cells, RNase L in P RL tumours was mea sured by Western blot analysis in tumour extracts using a monoclonal antibody to human RNase L. As shown, the expression of RNase L was completely shut down in the $\mathrm{P}$ RL tumours, suggesting that RNase L plays an important role in the inhibition of tumour growth (Fig. 6).

\section{Discussion}

RNase L has been suggested to function as a tumour suppres sor based on its roles in mediating apoptosis and anti prolif erative activity of IFN. ${ }^{18}$ Our findings provide the first direct evidence that RNase $\mathrm{L}$ is able to inhibit tumour growth 
a

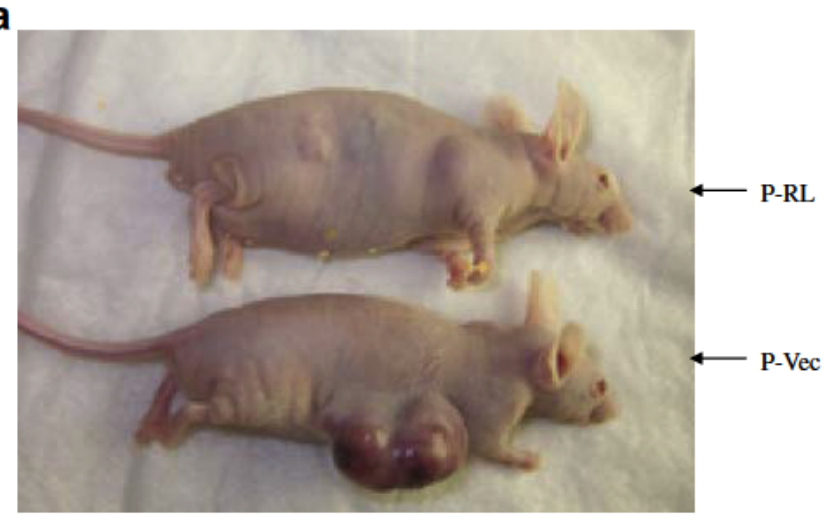

b

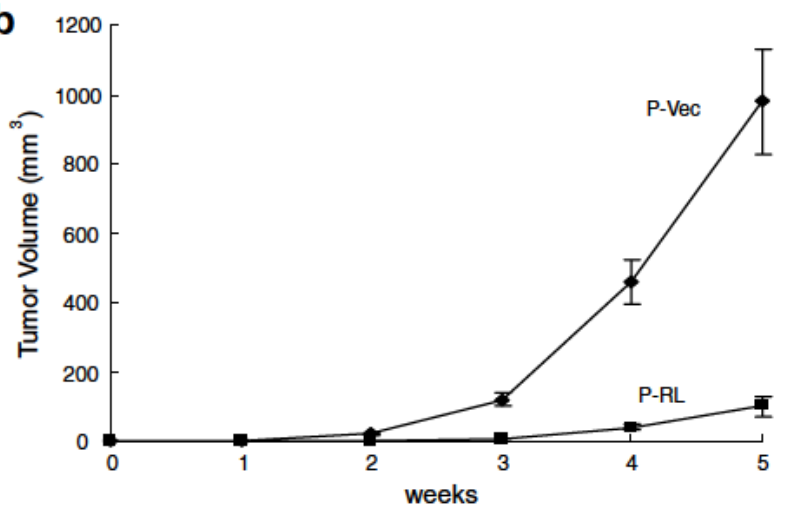

Fig. 4 - Overexpression of RNase L inhibits tumour growth. P-57 cells $\left(10^{6} / \mathrm{site}\right)$ transfected with pcDNAneo (P-Vec) or pcDNAneo/RNase L (P-RL) were injected subcutaneously into the flanks of groups of three nude mice. (a) Representative tumours and mice on day $\mathbf{3 0}$ after implantation with P-Vec and P-RL cells were shown. (b) Tumour volumes were determined using a caliper. Data are presented in means \pm SD. $P<0.003$ on day 30 in a paired Student's t-test.

in vivo. This result is consistent with the observation that mutations in the RNase $\mathrm{L}$ gene predispose men to an in creased incidence of prostate cancer. ${ }^{13-16}$ Interestingly, P RL cells eventually start to grow into tumours as a result of com

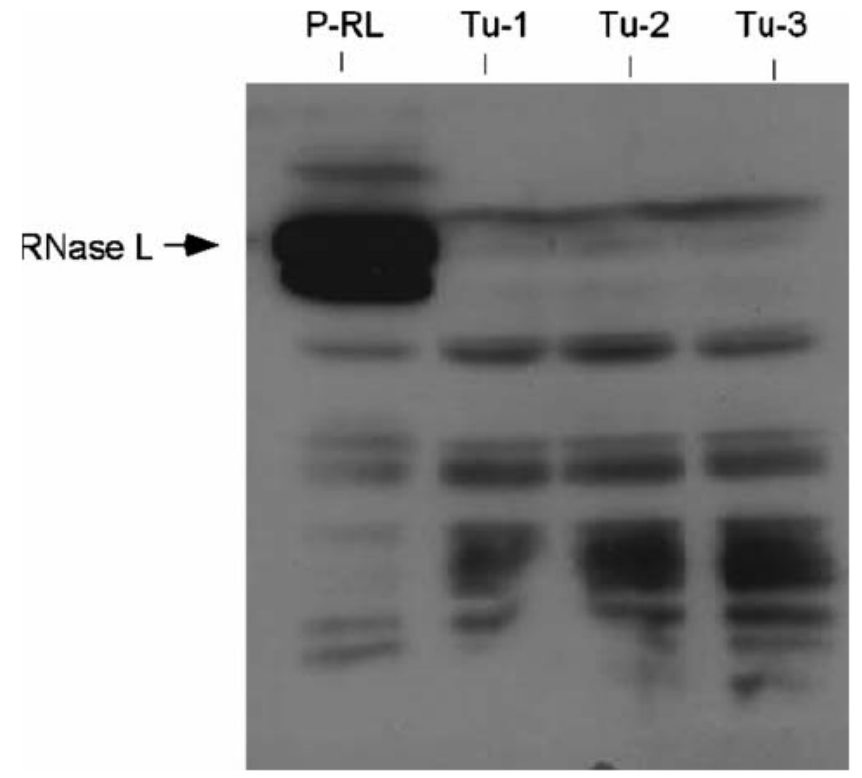

Fig. 6 - Suppression of RNase $\mathrm{L}$ expression in tumour. P-RL tumours on day 36 were dissected and homogenised in NP40 buffer. The expression of RNase L was determined by Western blot with a monoclonal antibody against human RNase L. P-RL: P-RL cells; Tu 1-3: P-RL tumor 1-3.

pletely blocking the expression of RNase L, further confirming the tumour suppressive function of RNase L.

It has been demonstrated that RNase L plays an important role in the effect of IFNs against viral infections and cellular proliferation. The activators of RNase L, 2 5A, are generated from ATP by the dsRNA activated 2 5A synthetases, a family of enzymes induced by the IFN treatment of mammalian cells. The only well established function of $25 \mathrm{~A}$ is to activate RNase L, that subsequently cleaves single strand RNA, result ing in the inhibition of both viral replication and cellular pro liferation. Natural $25 \mathrm{~A}$ molecules are very unstable and degraded by a combination of $5^{\prime}$ phosphatase and $2^{\prime}, 5^{\prime}$ phos phodiesterase present in cells. Therefore, in the absence of IFN and viral infection, 2 5A levels are either very low or ab sent. Our results have shown that although IFN treatment
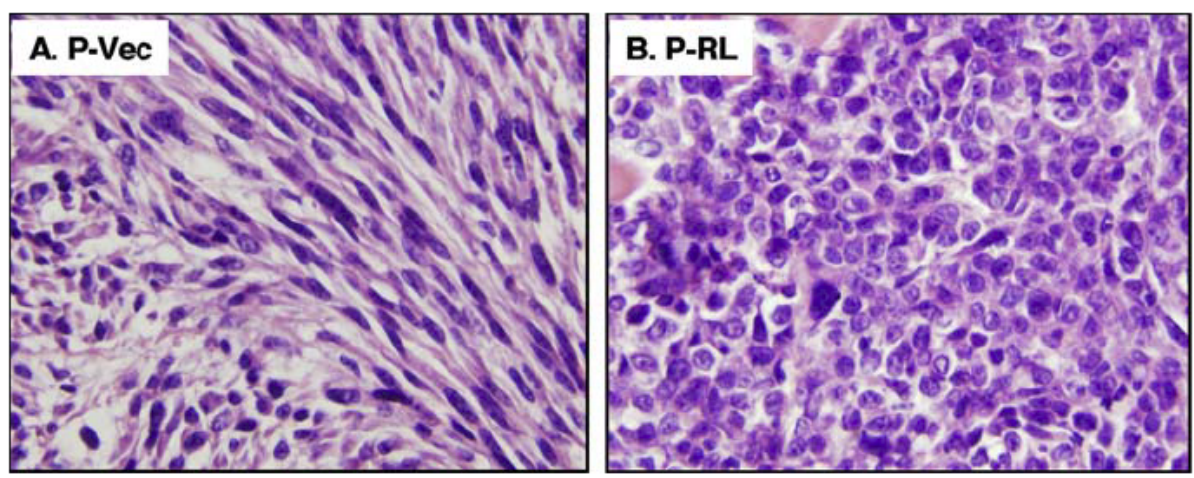

Fig. 5 - Distinctive cellular morphology of P-Vec and P-RL tumours. P-Vec and P-RL tumours recovered by necropsy at day 30 after cell implantation were fixed in $10 \%$ Formalin, routinely processed and sectioned, and stained with H\&E. Photomicrographs $(600 \times)$ shown here are representative of multiple fields examined in tumours excises from two independent experiments. 
produces an enhanced anti proliferative effect on MEFs, RNase $\mathrm{L}$ is able to inhibit cell proliferation independent of IFN (Fig. 1a). In addition, RNase $\mathrm{L}$ also regulates the growth of bone marrow cells in the presence of GM CSF, suggesting a broader role of RNase $\mathrm{L}$ in mediating cell proliferation (Fig. 1b). Surprisingly, we found that the overexpression of RNase L suppressed the tumour cell growth although there was no significant difference between P RL and P Vec cells in response to IFN (Fig. 2b). The expression of RNase $\mathrm{L}$ is cell specific. The expression level of RNase $L$ in certain cell types such as B cells, lymphoblasts, myelobasts and monocytes is about 2030 fold higher than that in fibroblasts (our unpub lished data). How these cells survive with the extremely high level of RNase $\mathrm{L}$ remains to be investigated.

RNase L is believed to display its biological function through regulating mRNA stability after IFN treatment. Ribo somal and viral RNAs have been the first reported targets of RNase L. Documented evidence has shown that RNase L plays an important role in the stability of several gene products, including IFN induced genes, such as ISG43, ISG15 ${ }^{19}$ and $\mathrm{PKR}^{20}$ in RNase L null cells; MyoD mRNA in myocytes ${ }^{21}$ and mitochondrial mRNAs in H9 lymphocytes. ${ }^{22}$ However, in the absence of viral infection, the sources of dsRNA and $25 \mathrm{~A}$ to activate $25 \mathrm{~A}$ synthetase, and RNase $\mathrm{L}$ remain obscure. It is possible that RNase $\mathrm{L}$ can indirectly regulate gene expression through interacting with other proteins because RNase L con tains structurally nine ankyrin repeats, a typical protein pro tein interaction domain. Recently, Peltz's group has demonstrated that RNase $\mathrm{L}$ is indeed able to regulate gene expression by interacting with another protein. ${ }^{23}$ They dis covered that RNase L can interact with human translation ter mination factor eRF3/GSPT1 to modulate the translation termination process, resulting in regulating gene expression. Their results outline a novel role for RNase $L$ as a regulator of translation.

The effect of RNase L on cell growth was not obvious when cells were grown at a low density (Fig. 3a). However, when cells grew at a high density, the morphological difference be tween these two cell lines was dramatic. P Vec cells grew more aggressively. Even though the cells have grown to con fluence, $\mathrm{P}$ Vec cells continued to grow, and piled up to form individual clones if fresh medium was provided. P RL cells ceased growing after cells became confluent. These cells were large and had a polygonal shape, probably due in part to the altered cell morphology. Furthermore, anchorage indepen dent growth in soft agar (Fig. 3b) is consistent with the obser vation in tumour formation in nude mice (Fig. 4a). These findings indicate a role of RNase $\mathrm{L}$ in suppressing tumour growth. Surprisingly, no spontaneous tumour formation has been observed in one year old RNase L ' mice. Currently, the effect of RNase on tumourigenesis induced by carcino gens is under investigation in our laboratory. We are also cross breeding RNase L ' with P53 / mice to determine whether $\mathrm{P} 53$ / mice deficient RNase L results in an increase of spontaneous tumour formation.

The P Vec tumours showed typical fibrosarcoma histology with fascicular, herringbone growth pattern and slender spin dled cells. However, with the overexpression of RNase L, the tumour cells demonstrated polymorphism with more epith eloid cells. Since RNase L is involved in the regulating the acti vation of the JNK pathway, which roles in the control of cell motility and morphogenesis have been well established, ${ }^{24}$ overexpression of RNase L may affect JNK regulated cytoskel etal molecules, and therefore cause the morphological alter ation. Interestingly, increased single cell necrosis was observed in P RL tumours. Whether the increased cell death is due to the overexpression of RNase L promoting apoptosis needs to be further investigated. ${ }^{9-11}$

\section{Conflict of interest statement}

None declared.

\section{Acknowledgements}

We are grateful to Dr. Crystal Weyman for the helpful com ments on the manuscript. This work was supported by the American Cancer Society Cleveland Pilot Grant and Estab lished Full time Faculty Research Development Award from Cleveland State University to A.Z.

R E F E R E N C E S

1. Stark GR, Kerr IM, Williams BR, Silverman RH, Schreiber RD. How cells respond to interferons. Annu Rev Biochem 1998;67:227 64 .

2. Kerr IM, Brown RE. pppA2'p5'A2'p5'A: an inhibitor of protein synthesis synthesized with an enzyme fraction from interferon treated cells. Proc Natl Acad Sci USA 1978;75(1):256 60.

3. Hovanessian AG, Brown RE, Kerr IM. Synthesis of low molecular weight inhibitor of protein synthesis with enzyme from interferon treated cells. Nature 1977;268:537 9.

4. Chebath J, Benech P, hovanessian A, Galabru J, Revel M. Four different forms of interferon induced 25 oligoA synthetase identified by immunoblotting in human cells. J Biol Chem 1978;262:3852 7.

5. Zhou A, Paranjape JM, Hassel BA, et al. Impact of RNase L overexpression on viral and cellular growth and death. $J$ Interferon Cytokine Res 1998;18(11):953 61.

6. Hassel BA, Zhou A, Sotomayor C, Maran A, Silverman RH. A dominant negative mutant of $25 \mathrm{~A}$ dependent RNase suppresses antiproliferative and antiviral effects of interferon. EMBO J 1993;12:3297 304.

7. Zhou A, Paranjape J, Brown TL, et al. Interferon action and apoptosis are defective in mice devoid of $2^{\prime}, 5^{\prime}$ oligoadenylate dependent RNase L. EMBO J 1997;16(21):6355 63.

8. Silverman RH. 25 A dependent RNase L: a regulated endoribonuclease in the interferon system. In: D'alessio G, Riordan JF, editors. Ribonucleases: structure and function. New York: Academic Press Inc.; 1996. p. 51747.

9. Rusch L, Zhou A, Silverman RH. Caspase dependent apoptosis by $2^{\prime}, 5^{\prime}$ oligoadenylate activation of RNase $\mathrm{L}$ is enhanced by IFN beta. J Interferon Cytokine Res 2000;20(12):1091 100.

10. Castelli JC, Hassel BA, Maran A, et al. The role of $2^{\prime} 5^{\prime}$ oligoadenylate activated ribonuclease $\mathrm{L}$ in apoptosis. Cell Death Differ 1998;5(4):313 20.

11. Castelli JC, Hassel BA, Wood KA, et al. A study of the interferon antiviral mechanism: apoptosis activation by the 2 5A system. J Exp Med 1997;186(6):967 72.

12. Li G, Xiang Y, Sabapathy K, Silverman RH. An apoptotic signaling pathway in the interferon antiviral response 
mediated by RNase L and c Jun NH2 terminal kinase. J Biol Chem 2004;279(2):1123 31.

13. Carpten J, Nupponen N, Isaacs S, et al. Germline mutations in the ribonuclease $\mathrm{L}$ gene in families showing linkage with HPC1. Nature Genet 2002;30:181 4.

14. Wang L, McDonnell SK, Elkins DA, et al. Analysis of the RNASEL gene in familial and sporadic prostate cancer. Am J Hum Genet 2002;71(1):116 23.

15. Rokman A, Ikonen T, Seppala EH, et al. Germline alterations of the RNASEL gene, a candidate HPC1 gene at 1q25, in patients and families with prostate cancer. Am J Hum Genet 2002;70(5):1299 304.

16. Casey G, Neville PJ, Plummer SJ, et al. RNASEL ARG462GLN variant is implicated in up to $13 \%$ of prostate cancer cases. Nature Genet 2002;32:581 3.

17. Zhou A, Paranjape JM, Der SD, Williams BR, Silverman RH. Interferon action in triply deficient mice reveals the existence of alternative antiviral pathways. Virology 1999;258:435 40.

18. Silverman RH. Implications for RNase L in prostate cancer biology. Biochemistry 2003;42:1805 12.

19. Li XL, Blackford JA, Judge CS, et al. RNase L dependent destabilization of interferon induced mRNAs. A role for the 2
$5 \mathrm{~A}$ system in attenuation of the interferon response. J Biol Chem 2000;275(12):8880 8.

20. Khabar KS, Siddiqui YM, Al Zoghaibi F, et al. RNase L mediates transient control of interferon response through modulation of the double stranded RNA dependent protein kinase PKR. J Biol Chem 2003;278(22):20124 32.

21. Bisbal C, Silhol M, Laubenthal H, et al. The $2^{\prime} 5^{\prime}$ oligoadenylate/RNase L/RNase L inhibitor pathway regulates both MyoD mRNA stability and muscle cell differentiation. Mol Cell Biol 2000;20(14):4959 69.

22. Le Roy F, Bisbal C, Silhol M, Martinand C, Lebleu B, Salehzada $\mathrm{T}$. The 2 5A/RNase L/RNase L inhibitor (RLI) [correction of (RNI)] pathway regulates mitochondrial mRNAs stability in interferon alpha treated $\mathrm{H} 9$ cells. J Biol Chem 2001;276(51):48473 82.

23. Le Roy F, Salehzada T, Bisbal C, Dougherty JP, Peltz SW. A newly discovered function for RNase L in regulating translation termination. Nat Struct Mol Biol 2005;12(6): 50512.

24. Xia Y, Karin M. The control of cell motility and epithelial morphogenesis by Jun kinases. Trends Cell Biol 2004;14: 94101. 